\title{
Maxillofacial Fractures in the Province of Pescara, Italy: A Retrospective Study
}

\author{
Giuliano Ascani, ${ }^{1}$ Francesca Di Cosimo, ${ }^{2}$ Michele Costa, ${ }^{2}$ \\ Paolo Mancini, ${ }^{1}$ and Claudio Caporale ${ }^{2}$ \\ ${ }^{1}$ Department of Maxillofacial Surgery, Spirito Santo Hospital, Via Fonte Romana 8, 65124 Pescara, Italy \\ ${ }^{2}$ Department of Otorhinolaryngology, Spirito Santo Hospital, Via Fonte Romana 8, 65124 Pescara, Italy \\ Correspondence should be addressed to Giuliano Ascani; giulianoascani@gmail.com
}

Received 4 November 2013; Accepted 3 December 2013; Published 23 January 2014

Academic Editors: K. Ishikawa and G. Ottaviano

Copyright (C) 2014 Giuliano Ascani et al. This is an open access article distributed under the Creative Commons Attribution License, which permits unrestricted use, distribution, and reproduction in any medium, provided the original work is properly cited.

The aim of the present study was to assess the etiology and pattern of maxillofacial fractures in the Province of Pescara, Abruzzo, Central Italy. Was performed a retrospective review of patients treated at the Department of Maxillofacial Surgery of Spirito Santo Hospital from January 2010 to December 2012. Data collected and analyzed included sex, age, cause of injury, site of fracture, monthly distribution, and alcohol misuse. A total of 306 patients sustaining 401 maxillofacial fractures were treated. There were 173 males (56.5\%) and 133 females (43.5\%). Most of the patients (36.9\%) were in the age group of $18-44$ years. The most common causes of injuries were road traffic accidents (26.4\%); the second leading cause was interpersonal violence (23.2\%), followed by injuries associated with falls $(19.2 \%)$. Fractures of the mandible $(31 \%)$ and zygoma (23\%) were the most common maxillofacial fractures in our study. The monthly distribution peaked in the summer (July and August, 30.4\%) and in October (13.1\%). In conclusion, this study confirms the close correlation between the incidence and etiology of facial fractures and the geographical, cultural, and socioeconomic features of a population. The data obtained provide important information for the design of future plans for injury prevention and for education of citizens.

\section{Introduction}

There is a remarkable regional variation in the incidence, sex and age distributions, aetiology, and site distribution of maxillofacial fractures depending upon the geographic conditions, cultural characteristics, and socioeconomic trends [1-6].

The Province of Pescara is a province in the Abruzzo region of Italy; it has an area of $1.187 \mathrm{~km}^{2}$ and a total population of 314.391 inhabitants.

Since the Department of Maxillofacial Surgery in the Hospital of Pescara was opened in January 2010 acting as facial trauma centre, no study has been carried out so far to find out the epidemiological data of maxillofacial fractures in our province.

We therefore assessed the etiology and pattern of maxillofacial fractures in patients treated at our centre with the aim to give valuable information for both health care providers and government officials that can be used for the development of public health programs for education and prevention.

\section{Materials and Methods}

We have carried out a retrospective analysis of all patients with maxillofacial fractures surgically treated at the Department of Maxillofacial Surgery of Spirito Santo Hospital, Pescara, Italy, from January 2010 to December 2012.

Data collected and analyzed included sex, age, cause of injury, site of fracture, monthly distribution, and alcohol misuse.

The aetiological factors were classified into road traffic accidents (RTA), interpersonal violence, falls, work- related accidents, and others (iatrogenic, gunshot, pathological, etc.).

In patients with multiple facial bone fractures, each affected bone was evaluated as separate case. 


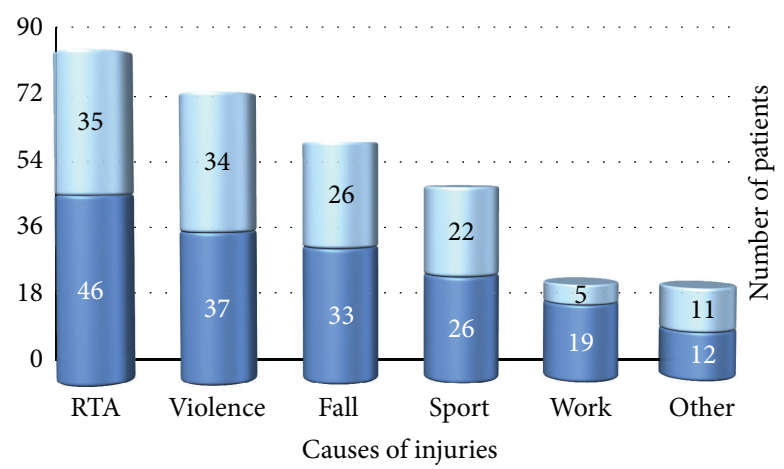

Males (Tot. 173)

Females (Tot. 133)

FIGURE 1: Distribution of patients according to gender and causes of injuries.

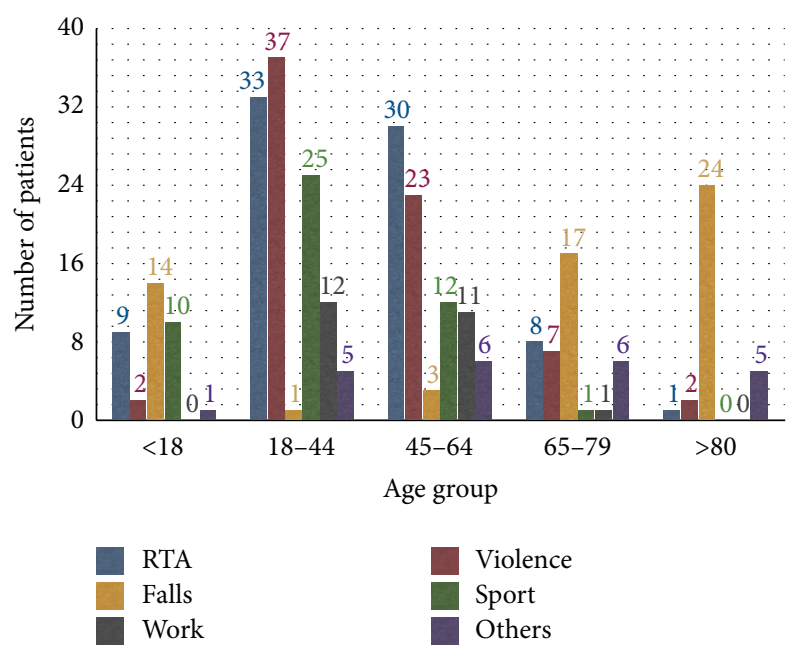

FIGURE 2: Distribution of patients according to age group and causes of fractures.

Patients with dentoalveolar fractures and patients with nasal bone fractures were excluded from the study because in our hospital they are treated by dentist and otorhinolaryngologist, respectively.

\section{Results}

A total of 306 patients sustaining 401 maxillofacial fractures were treated at our centre between January 2010 and December 2012.

There were 173 males (56.5\%) and 133 females (43.5\%), giving a male to female ratio of $1.3: 1$. Distribution of patients according to gender and causes of injuries is shown in Figure 1.

Most of the patients $(125 ; 36.9 \%)$ were in the age group of $18-44$ years, while the smallest number of patients $(32 ; 10.4 \%)$ was over the age of 80 . Distribution of patients according to age group and causes of fractures is shown in Figure 2.
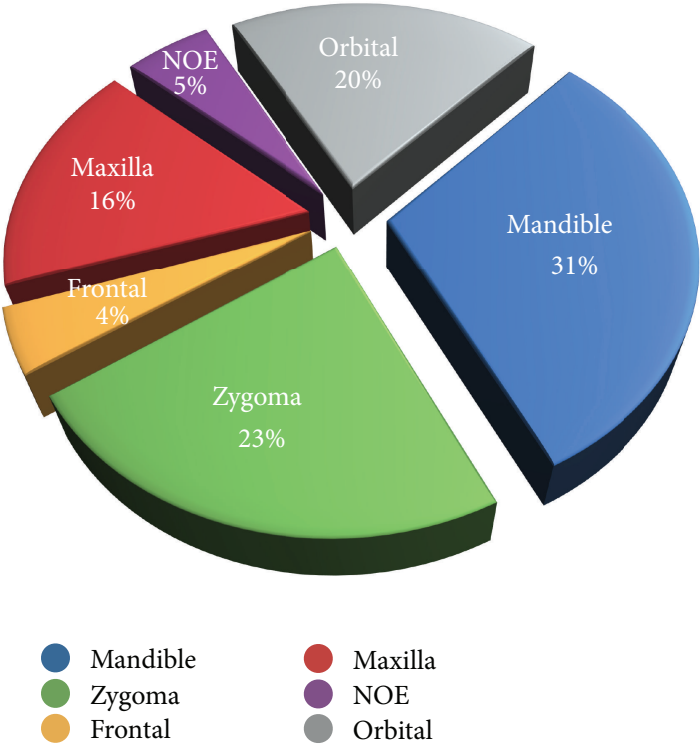

FIgURE 3: Site distribution of fractures.

The most common causes of injuries were road traffic accidents (81 patients; $26.4 \%$ ); out of these 81 patients, 35 (43.2\%) were involved in bicycle accidents, 24 (29.6\%) in motorcycle accidents, and $22(27.2 \%)$ in car accidents.

The second leading cause was interpersonal violence (71 patients; $23.2 \%$ ), followed by injuries associated with falls accounting for 59 (19.2\%) of all injuries; out of these 59 patients, 56 (94.9\%) injuries were associated with falls on the ground and $3(5.1 \%)$ with falls from height.

Sport-related injuries were documented in 48 (15.7\%) patients: 23 playing soccer, 6 rugby, 6 capoeira, 12 bicycle racing, 1 volleyball, and 1 basketball.

Work-related injuries caused maxillofacial fracture in 24 (7.8\%) patients.

In 23 (7.5\%) patients other causes were recorded: 11 pathological fractures, 8 iatrogenic fractures, 2 collision with a heavy object, 1 hit by horse kick, and 1 gunshot.

Out of the total of 306 patients, 91 (29.7\%) presented two or more sites of fractures, average 1.3 fractures per patient; panfacial fractures were treated in $11(3.6 \%)$ patients.

Fractures of the mandible (123; 31\%) and zygoma (92; $23 \%$ ) were the most common; site distribution of fractures is shown in Figure 3.

Among the 306 patients, 121 (39.5\%) were under the effect of alcohol at the time of injury.

The monthly distribution peaked in the summer (July and August, 30.4\%) and in October (13.1\%); in Figure 4 is shown the yearly and monthly distribution of maxillofacial fractures.

\section{Discussion}

The epidemiological features of maxillofacial fractures are consistently influenced depending on environmental, cultural, and socioeconomic factors, with great variations among 


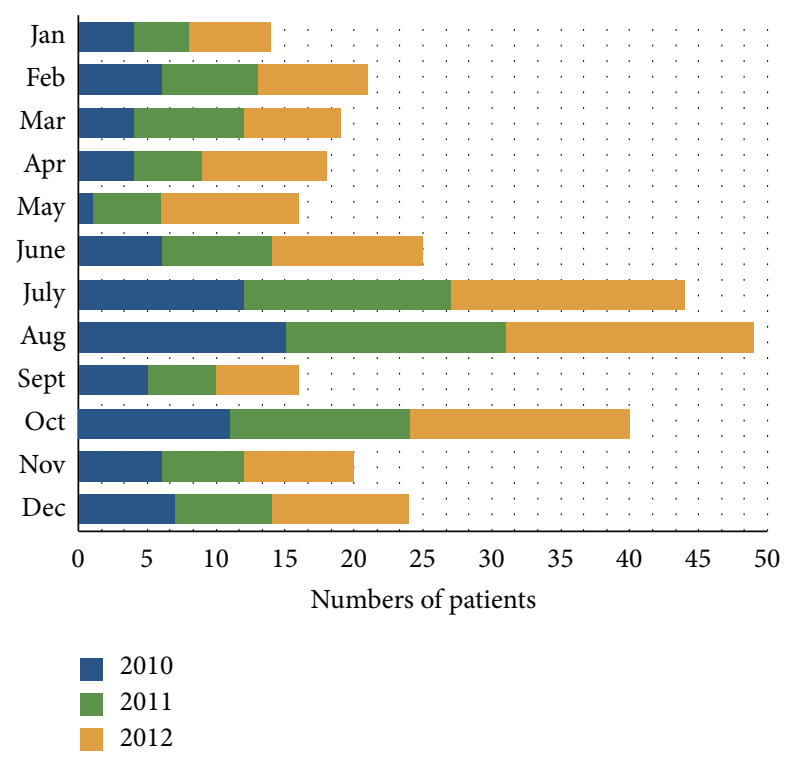

FIgURE 4: Yearly and monthly distribution of maxillofacial fractures.

populations of different countries and even within the same country [1-7].

Like previous studies, our finding shows that maxillofacial fractures are more common in males, but the male to female ratio in our study $(1.3: 1)$ was lower than those reported in the international literature [3-8].

In this study, the peak incidence was in the age group of 18-44 years, in agreement with the results of many other authors $[3,4,9]$ and reflecting the fact that people in the third decade of life are more active regarding work, sports, violent activities, and high speed transportation.

As throughout the world [3,9-12] even in our province the primary causes of maxillofacial fractures are road traffic accidents, interpersonal violence, and falls. According to this study, road traffic accidents remain the leading cause of injuries in both males and females, although the numbers of females injured by road traffic accidents and by interpersonal violence are practically equal (35 versus 34 ) (Figure 1 ). In contrast to other previous reports $[2,9,11,12]$, violencerelated fractures proved to be higher in females $(25.6 \%)$ than in males $(21.4 \%)$. In this study, interpersonal violence is the main cause of maxillofacial fractures in patients between 18 and 44 years while falls were the most common cause in children ( $<18$ years) and the elderly ( $>65$ years) (Figure 2$)$.

Among road traffic accidents, two wheelers were responsible for the majority of maxillofacial fractures (59 patients; $72.8 \%$ of RTAs); these results were similar to previous studies reported in the literature $[2,3,10,11]$ and can be explained by the fact that bicycles and motorcycles are very popular as means of transport in our province because of its geographical and climatic features.

Among sports-related fractures we reported 6 patients injured by playing capoeira. All of these patients were treated in a period time of 5 months, between September 2011 and January 2012; this is due to the fact that during that period there was a large spread in Italy of capoeira and many people have started to practice this sport. This data confirms the variability over time of the etiology of maxillofacial trauma and the close correlation with the sociocultural trends.

In the present series, the most commonly involved bones were the mandible followed by zygoma. These reports are consistent with studies in several other countries $[2-4,9,10]$ but in contrast with one recent study from Italy [13] that indicates the zygoma as the most fractured anatomical site, followed by isolated fractures of the orbital floor.

Our study shows a close association between maxillofacial injuries and alcohol consumption (39.5\% of patients); these findings are similar with previous studies from several countries $[3,10,14,15]$. Alcohol significantly impairs judgment and coordination, facilitates aggression and interpersonal violence, and is a major cause of road traffic accidents.

The monthly distribution of the maxillofacial fractures in our province showed two peaks.

The first one was in July-August and was related to the tourist season during which there is an exponential increase of population in our territory. This was similar to other studies $[4,13]$. The second peak was in October and can be explained by the olive-harvesting season. In our province, there is a long tradition of olive oil production that is often a family activity. For this many people, even the elderly and those with little experience, are involved in the olive harvest, resulting in significant number of maxillofacial traumas related to it.

\section{Conclusions}

This study confirms the close correlation between the incidence and etiology of facial fractures and the geographical, cultural, and socioeconomic features of a population.

The data obtained provide important information for the design of future plans for injury prevention and for education of citizens.

\section{Conflict of Interests}

The authors declare that there is no conflict of interests regarding the publication of this paper.

\section{References}

[1] A. Kraft, E. Abermann, R. Stigler et al., "Craniomaxillofacial trauma: synopsis of 14, 654 cases with 35, 129 injuries in 15 years," Craniomaxillofacial Trauma and Reconstruction, vol. 5, no. 1, pp. 41-50, 2012.

[2] B. van den Bergh, K. H. Karagozoglu, M. W. Heymans, and T. Forouzanfar, "Aetiology and incidence of maxillofacial trauma in Amsterdam: a retrospective analysis of 579 patients," Journal of Cranio-Maxillofacial Surgery, vol. 40, no. 6, pp. e165-e169, 2012.

[3] R. Bali, P. Sharma, A. Garg, and G. Dhillon, "A comprehensive study on maxillofacial trauma conducted in Yamunanagar, India," Journal of Injury and Violence Research, vol. 5, no. 2, pp. 108-116, 2013.

[4] A. Mijiti, W. Ling, M. Tuerdi et al., "Epidemiological analysis of maxillofacial fractures treated at a university hospital, Xinjiang, 
China: a 5-year retrospective study," Journal of Cranio-MaxilloFacial Surgery, 2013.

[5] M. H. Ansari, "Maxillofacial fractures in Hamedan province, Iran: a retrospective study (1987-2001)," Journal of CranioMaxillofacial Surgery, vol. 32, no. 1, pp. 28-34, 2004.

[6] H. E. A. Ahmed, M. A. Jaber, S. H. Abu Fanas, and M. Karas, "The pattern of maxillofacial fractures in Sharjah, United Arab Emirates: a review of 230 cases," Oral Surgery, Oral Medicine, Oral Pathology, Oral Radiology and Endodontology, vol. 98, no. 2, pp. 166-170, 2004.

[7] H. H. Zhou, D. Ongodia, Q. Liu, R. T. Yang, and Z. B. $\mathrm{Li}$, "Changing pattern in the characteristics of maxillofacial fractures," Journal of Craniofacial Surgery, vol. 24, no. 3, pp. 929933, 2013.

[8] A. Bakardjiev and P. Pechalova, "Maxillofacial fractures in Southern Bulgaria-a retrospective study of 1706 cases," Journal of Cranio-Maxillofacial Surgery, vol. 35, no. 3, pp. 147-150, 2007.

[9] A. N. Shankar, V. N. Shankar, N. Hegde, S. Sharma, and R. Prasad, "The pattern of the maxillofacial fractures-a multicentre retrospective study," Journal of Cranio-Maxillofacial Surgery, vol. 40, no. 8, pp. 675-679, 2012.

[10] W. M. van Hout, E. M. van Cann, J. H. Abbink, and R. Koole, "An epidemiological study of maxillofacial fractures requiring surgical treatment at a tertiary trauma centre between 2005 and 2010," The British Journal of Oral and Maxillofacial Surgery, vol. 51, no. 5, pp. 416-420, 2013.

[11] E. G. Salentijn, B. van den Bergh, and T. Forouzanfar, "A tenyear analysis of midfacial fractures," Journal of Cranio-MaxilloFacial Surgery, vol. 41, no. 7, pp. 630-636, 2013.

[12] G. Kostakis, P. Stathopoulos, P. Dais et al., "An epidemiologic analysis of 1,142 maxillofacial fractures and concomitant injuries," Oral Surgery, Oral Medicine, Oral Pathology, Oral Radiology and Endodontology, vol. 114, no. 5, supplement, pp. S69-S73, 2012.

[13] P. Arangio, V. Vellone, U. Torre, V. Calafati, M. Capriotti, and P. Cascone, "Maxillofacial fractures in the province of Latina, Lazio, Italy: review of 400 injuries and 83 cases," Journal of Cranio-Maxillo-Facial Surgery, 2013.

[14] S. Laverick, N. Patel, and D. C. Jones, "Maxillofacial trauma and the role of alcohol," The British Journal of Oral and Maxillofacial Surgery, vol. 46, no. 7, pp. 542-546, 2008.

[15] J. L. R. Leles, E. J. dos Santos, F. D. Jorge, E. T. da Silva, and C. R. Leles, "Risk factors for maxillofacial injuries in a Brazilian emergency hospital sample," Journal of Applied Oral Science, vol. 18, no. 1, pp. 23-29, 2010. 


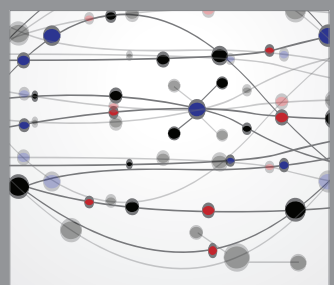

The Scientific World Journal
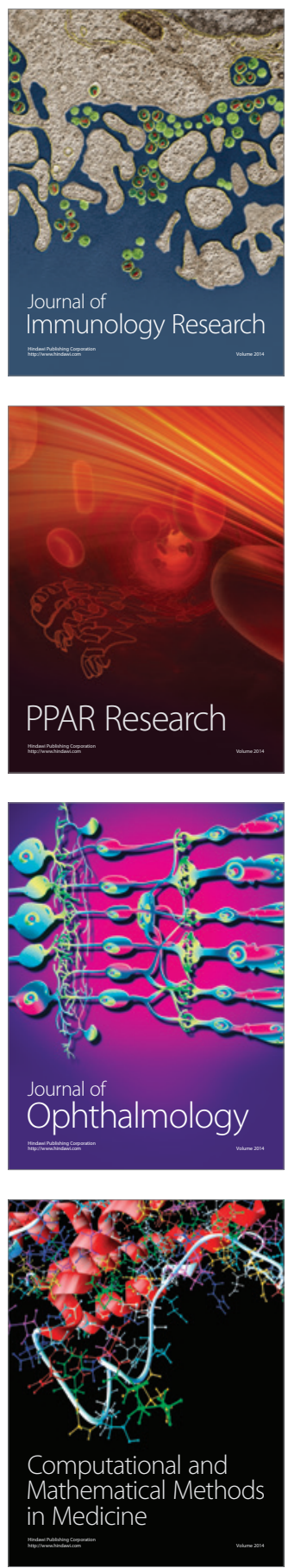

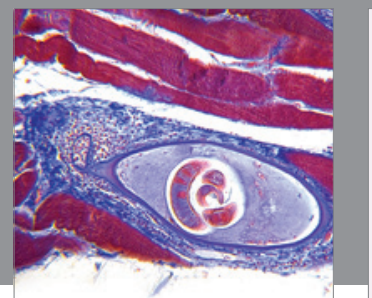

Gastroenterology

Research and Practice
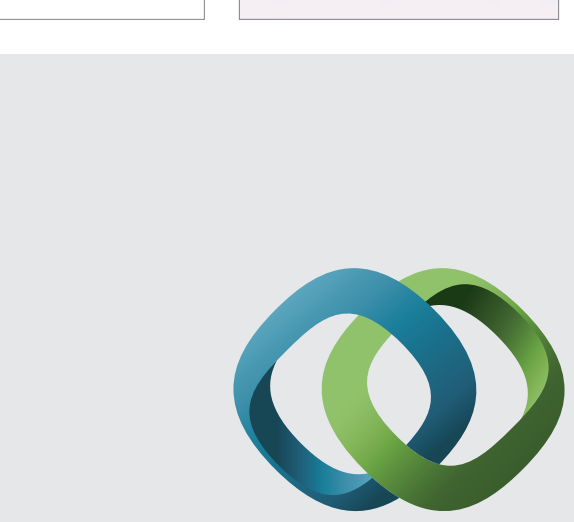

\section{Hindawi}

Submit your manuscripts at

http://www.hindawi.com
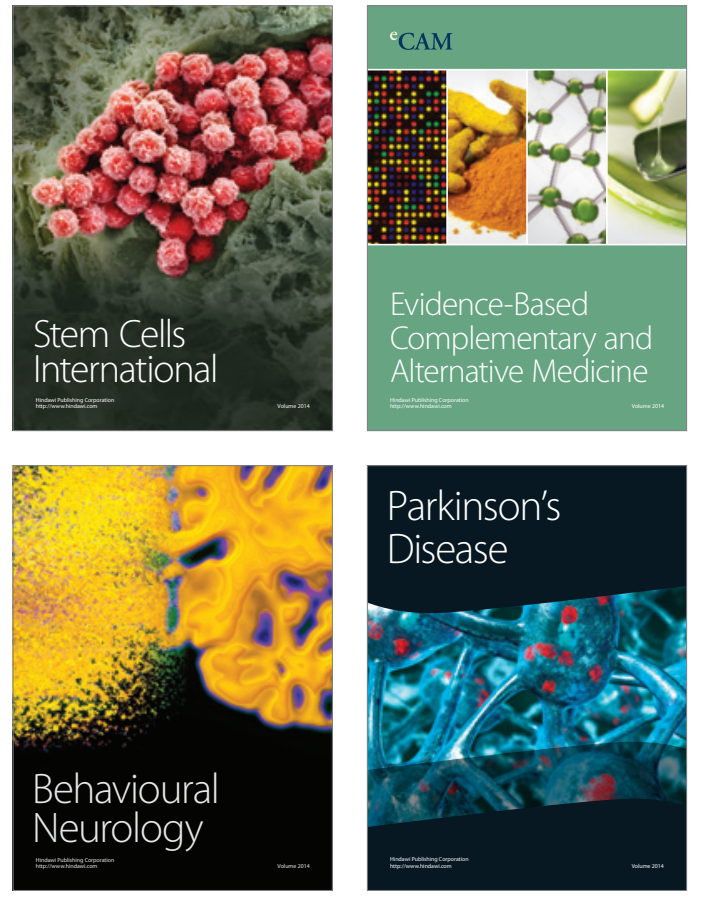
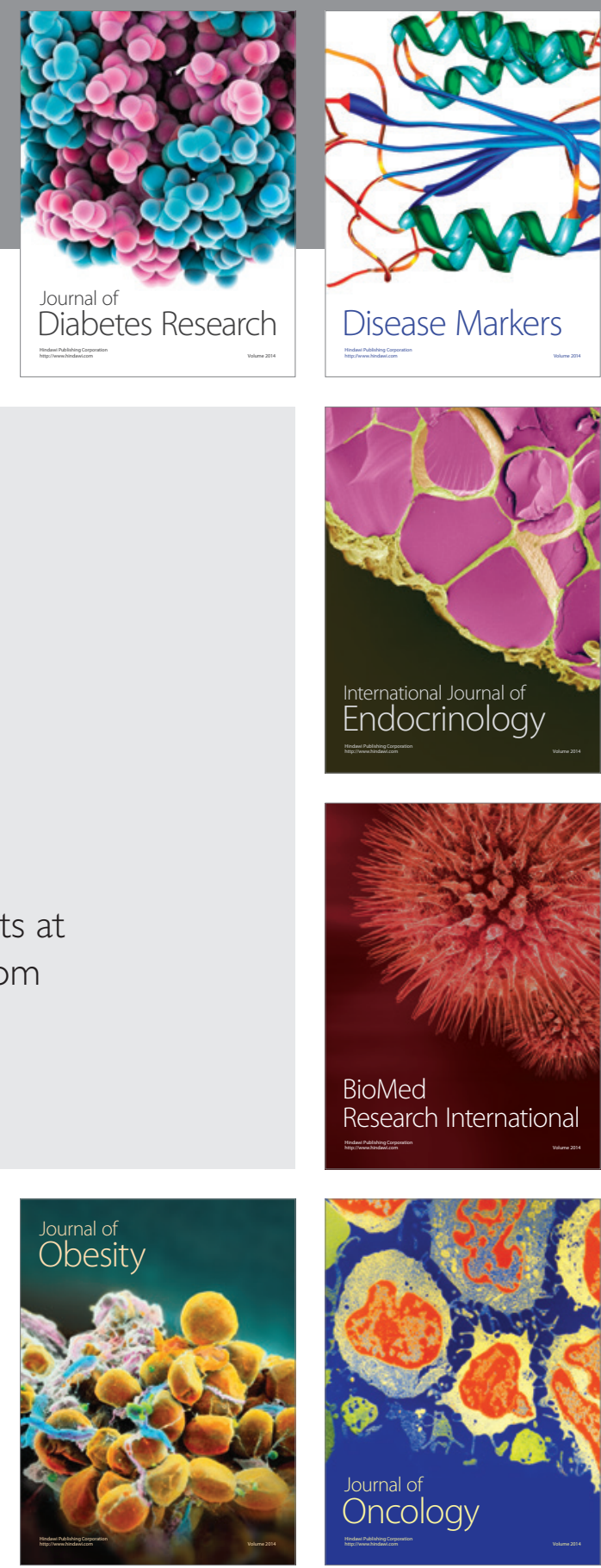

Disease Markers
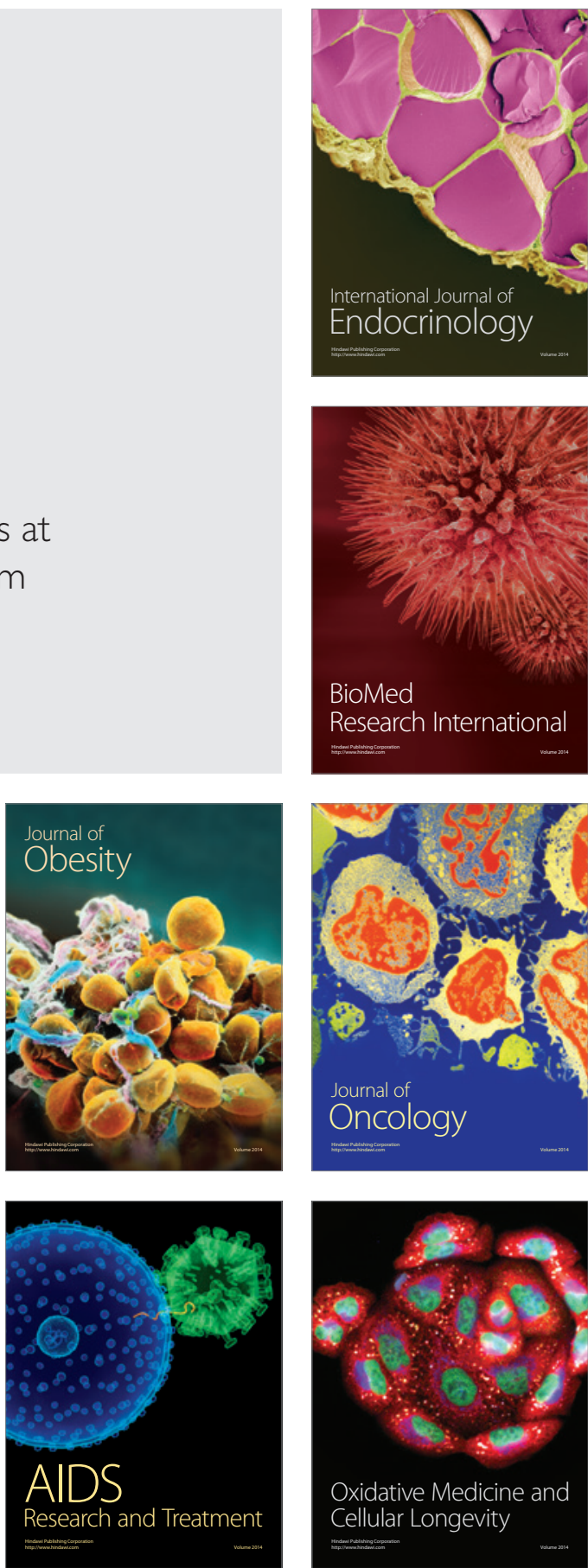